\title{
Breaking down bone: new insight into site-specific mechanisms of breast cancer osteolysis mediated by metalloproteinases
}

\author{
Theresa A. Guise ${ }^{1}$ \\ Endocrinology and Metabolism, Department of Internal Medicine, Indiana University School of Medicine, Indianapolis, Indiana \\ 46202, USA
}

Bone metastases are the most common skeletal complication of malignancy. Tumor cells disrupt normal bone remodeling to promote bone destruction and its associated morbidity. In the August 15, 2009, issue of Genes \& Development, Lu and colleagues (pp. 18821894) propose a novel molecular mechanism by which tumor-produced metalloproteinases release epidermal growth factor (EGF) ligands to activate the central osteoclastogenic pathway receptor activator of NF- $\kappa B$ ligand (RANKL) to promote breast cancer osteolysis. This work has important therapeutic applications that may quickly translate to more effective treatment for bone metastases.

Bone metastases are common in breast, prostate, and lung cancer, and are associated with significant morbidity. Unique aspects of the bone microenvironment—such as mineralized bone matrix, which houses immobilized growth factors, bone-destroying osteoclasts, and boneforming osteoblasts-make it a fertile soil for these cancers to grow. Significant insight into the molecular mechanisms responsible for the proclivity of tumors to metastasize and grow in bone has been gleaned in recent years from mouse models and clinical studies. Bone destruction mediated by solid tumor metastases to bone, particularly in breast cancer, is driven by tumor stimulation of osteoclastic bone resorption. Collective evidence supports the notion that effective therapy for bone metastases should target both the tumor and the bone microenvironment. Indeed, bisphosphonate therapy to block osteoclastic bone resorption, used in conjunction with standard anti-cancer treatments, reduces bone pain, pathologic fracture, and hypercalcemia associated with bone metastases from all tumor types. However, regression and cure of bone metastases have yet to be achieved with the current therapeutic armamentarium. Thus,

[Keywords: EGFR; bone metastasis; breast cancer; metalloprotease; osteoclastogenesis]

${ }^{1}$ Correspondence.

E-MAIL tguise@iupui.edu; FAX (317) 278-0658.

Article is online at http://www.genesdev.org/cgi/doi/10.1101/gad.1854909. a better understanding of the molecular mechanisms responsible for this devastating skeletal complication of malignancy is required to develop more effective therapy, with the eventual goal of curing and preventing bone metastases. In the August 15, 2009, issue of Genes \& Development, Lu et al. (2009) bring the field closer to this goal. They describe an autocrine/paracrine signaling cascade triggered by metalloproteinases-matrix metalloproteinase-1 (MMP-1) and a disintegrin and metalloproteinase with thrombospondin motifs (ADAMTS1) - and cleavage of epidermal growth factor (EGF) ligands to reduce the ratio of osteoblast-produced receptor activator of NF- $\mathrm{B}$ ligand (RANKL) to osteoprotegerin (OPG) to favor osteoclastogenesis and promote breast cancer osteolysis. These studies, described herein, have important implications for new applications of standard cancer therapy that could result in more effective treatment for bone metastases.

Bone metastases: clinical features and current therapy

Certain solid tumors-such as breast, prostate, and lung cancer-have a propensity to metastasize to bone to cause bone pain, fracture, hypercalcemia, and paralysis. This morbidity is great: $\mathrm{Up}$ to $75 \%$ of advanced breast and prostate cancer and $30 \%-40 \%$ of lung cancer patients have bone metastases (Mundy 2002; Roodman 2004). The most devastating consequence is that once cancer has metastasized to bone it is incurable. Furthermore, patients with breast and prostate cancer bone metastases can survive for many years, during which they will suffer significant morbidity. In the United States alone, it is estimated that 350,000 people die with bone metastases due to breast and other cancers each year (Mundy 2002).

Bone metastases are classified as osteolytic or osteoblastic, based on radiographic appearance. In reality, most patients have components of both bone resorption and bone formation. Accumulating evidence, clinical and experimental, supports a pivotal role for the osteoclast in the pathogenesis of bone metastases, regardless of the radiographic phenotype. Bone resorption markers are increased in both osteolytic and osteoblastic solid tumor bone metastases and are higher in the latter (Lipton et al. 
2001). Bisphosphonates decrease skeletal morbidity from bone metastases from solid tumors or myeloma, whether osteolytic or osteoblastic (Lipton et al. 2002; Saad et al. 2002). Finally, the bone resorption marker N-telopeptide predicts death and skeletal morbidity from solid tumors, and this relationship is stronger in osteoblastic disease due to prostate cancer (Brown et al. 2005; Cook et al. 2006). Thus, osteoclasts are central to the pathogenesis of bone metastasis and the rationale to target this boneresorbing cell is strong.

Bisphosphonates are the only approved bone-targeted therapy to treat bone metastases. They effectively inhibit osteoclast function by inducing osteoclast apoptosis, and decrease skeletal-related events in patients with solid tumor bone metastasis. Despite this effectiveness, bisphosphonates do not cause regression of bone metastases, so new therapies are needed. Some limitations to the use of bisphosphonates include, but are not restricted to, an association with osteonecrosis of the jaw, recognized recently with potent intravenous bisphosphonates, especially in cancer patients (Khosla et al. 2007), and possible renal toxicity. Thus, better options to target the osteoclast for bone metastases and other disorders associated with increased bone resorption are needed.

\section{Pathophysiology of bone metastases: role of the bone microenvironment and consequent translational opportunities}

The bone microenvironment is unique and provides a fertile soil for breast and other cancers to thrive. Bone is a hard tissue, but a dynamic one that undergoes a continuous remodeling process to maintain bone strength. In a finely balanced process, osteoclasts resorb bone and osteoblasts replace the void with new bone. Pathologic states, such as cancer metastases, can disrupt this process to favor bone destruction. Mineralized bone matrix houses growth factors such transforming growth factor$\beta$ (TGF- $\beta$ ) and insulin-like growth factors (IGFs) that can promote metastases (Yin et al. 1999). Tumor-produced factors such as parathyroid hormone-related protein (PTHrP), interleukin-11 (IL-11), IL-6, and IL-8 stimulate bone resorption to release and activate growth factors housed in the mineralized bone matrix. Bone-derived TGF- $\beta$ promotes osteolysis by stimulating tumor production of osteolytic factors, and alters the bone microenvironment to further increase osteoclastic bone resorption and inhibit bone formation (Yin et al. 1999; Korpal et al. 2009; Mohammad et al. 2009). These tumor-bone interactions result in a feed-forward cycle to promote tumor growth in bone. An understanding of these local tumor-bone interactions is essential to develop more effective therapy.

The dominant pathway that controls osteoclastogenesis in health and disease is the RANKL signaling triad. RANKL, when bound to its cognate receptor RANK on the surface of osteoclast precursors, promotes osteoclastogenesis. OPG, a soluble decoy receptor for RANKL, inhibits osteoclast formation. It caused osteopetrosis in mice when overexpressed and protected from ovariectomy- induced bone loss (Simonet et al. 1997; Tsuda et al. 1997). Mice treated with RANKL developed hypercalcemia from increased osteoclastogenesis (Lacey et al. 1998). Both RANK-null and RANKL-null transgenic mice lack osteoclasts, demonstrating a requirement of RANKL signaling for osteoclast development (Lacey et al. 1998; Dougall et al. 1999; Kong et al. 1999).

OPG and RANKL are both expressed by osteoblasts and bone marrow stromal cells, and the ratio of these determine the degree of osteoclastogenesis, effectively balancing new bone formation and resorption in healthy bone. In cancer, the RANKL/OPG ratio is perturbed by signals from cancer cells, and excessive bone resorption or formation occurs. Tumor-produced PTHrP, IL-6, and IL-11 increase RANKL expression in osteoblasts (Horwood et al. 1998; Thomas et al. 1999; Palmqvist et al. 2002), while IL-8 increases osteoclastogenesis in both a RANKL-dependent and RANKL-independent manner (Bendre et al. 2003). In addition to enhancing bone resorption in response to cancer cell signals, RANKL, RANK, and OPG may also play a role in cancer cell proliferation, and migration to and invasion of bone (Jones et al. 2006).

Animal models of breast cancer bone metastases show survival increases with agents that target bone responses to tumor, such as increased osteoclastic bone resorption with bisphosphonates (Daubiné et al. 2007; Coleman 2009) or increased osteoblastic activity with endothelin receptor antagonists (Yin et al. 2003; James et al. 2009), rather than directly inhibiting tumor cells. Recent clinical trials have shown improved survival in breast (Coleman 2009) and prostate (James et al. 2009) cancer patients, respectively, treated with these agents. These recent results suggest that specific treatments for bone metastases may be most successful if they target skeletal responses to the tumor rather than the tumor alone.

\section{Bone metastasis genes}

The complexity of the metastatic cascade that results in bone metastases is illustrated by the study by Kang et al. (2003), in which MDA-MB-231 breast cancer clones with high capacity to metastasize to bone in a mouse model were compared with clones with low capacity by gene array analysis. Here, 11 putative bone metastases genes were increased in the clones with high bone metastasis capacity compared with those with low capacity. These genes encode for proteins that have specific actions on bone cells that disrupt normal bone remodeling to promote the establishment and progression of bone metastases. Four of these up-regulated genes were studied in detail with functional analysis in a bone metastasis mouse model. IL-11 stimulates osteoclastic bone resorption by increasing osteoblast production of RANKL. Connective tissue growth factor (CTGF) increases osteoblast proliferation (Kumar et al. 1999). The chemokine receptor CXCR4 binds to the osteoblast product, stromalderived factor-1 (SDF-1), to increase tumor homing to bone (Sun et al. 2005). Metalloproteinases MMP-1 and ADAMTS1 were also increased in the bone metastatic 
clones. Although MMPs have been widely implicated in cancer invasion and metastases and bone remodeling, their specific role in bone metastases and bone resorption has been less well defined. Kang et al. (2003) overexpressed these putative genes, alone and in combination, in the MDA-MB-231 clones with low bone metastases capacity. The high bone metastases phenotype could only be reproduced when three or more of the bone metastasis genes were overexpressed. These studies suggested that cancer cells express a toolbox of genes that encode proteins that have specific, but different, actions in the bone microenvironment to disrupt bone remodeling and promote bone destruction and, ultimately, tumor growth in bone. The exact role of the increased expression of the MMPs MMP-1 and ADAMTS1 was unclear, and set the stage for the present study by Lu et al. (2009).

\section{MMPs in bone, cancer, and bone metastases}

MMPs, zinc-dependent proteinases that cleave ECM substrates, have important functions in pathologic conditions where excessive degradation of ECM occurs, such as metastases and bone remodeling. MMPs clearly contribute to general metastases through mechanisms of angiogenesis, invasion, migration, and final colonization of the metastatic site (Coussens et al. 2002). Despite the clear association of MMPs to promote metastases, the wide range of MMPs and their ubiquitous nature have made it difficult to exploit them as therapeutic targets.

Clinical and experimental evidence support a role for the MMPs to promote osteoclastic bone resorption and bone metastases. The precise molecular mechanisms have been unclear (Egeblad and Werb 2002), but appear to involve proteolytic cleavage of substrates and subsequent activation of prometastatic factors-such as TGF- $\beta$, IGFs, and vascular endothelial growth factors (VEGFs) - and ultimate activation of the RANKL pathway. Bone matrix is comprised mostly of mineralized fibrillar type I collagen. MMPs are capable of cleaving native, nondenatured collagens with long uninterrupted triple helices and can function as collagenases in vivo. Several MMPs expressed in bone function in endochondral ossification during embryonic development and in modeling and remodeling of bone postnatally and later in life (Krane and Inada 2008). In support of the latter, mice homozygous for a targeted mutation in Col1a1 that are resistant to collagenase cleavage of type I collagen are resistant to $\mathrm{PTH}$-induced osteoclastic bone resorption (Zhao et al. 2000).

MMPs are increased in most cancers, including breast and prostate (Upadhyay et al. 1999; Bachmeier et al. 2001; Nemeth et al. 2002), and high levels of MMPs have been associated with poor prognosis (John and Tuszynski 2001; Nakopoulou et al. 2002, 2003; Ranuncolo et al. 2003). In an animal model of prostate cancer osteolytic bone metastasis, MMP-7-deficient mice had less osteolysis due to defective RANKL processing and reduced osteoclast activation (Lynch et al. 2005). MMPs are naturally inhibited by tissue inhibitors of MMPs (TIMPs) that can also inhibit the growth, invasion, and metastasis of malignant tumors. Expression of TIMP-2 in addition to bisphosphonate treatment markedly reduced the number of osteolytic lesions and increased overall survival compared with treatment with bisphosphonates alone (Yoneda et al. 1997). Increased MMP-9 activity correlated with osteoclast activity in a PC-3 prostate cancer model of osteolytic bone metastases. In a prospective study with 71 breast cancer patients with bone metastases, Costa et al. (2008) showed that serum ICTP (C-terminal telopeptide, generated by MMP-1 cleavage of type I collagen) and MMP-1 concentrations were associated with a shorter time to development of skeletal-related events.

Despite these convincing associations with MMPs and metastasis, the results of MMP inhibitor phase III clinical trials of generalized metastases have been disappointing (Coussens et al. 2002). One possibility for this failure could be that the studies were designed to measure outcomes of generalized metastases. Given recent evidence that a large number of MMPs are up-regulated in bone metastases (Kang et al. 2003; Nabha et al. 2008; Klein et al. 2009), primary outcome of bone metastases measurements may have been a more appropriate endpoint to demonstrate clinically significant differences with MMP inhibitors.

\section{Downstream effectors of MMPs: contributions to osteolysis}

This collective body of evidence indicates that a complex array of factors orchestrate important interactions between tumor and bone that promote the development and progression of bone metastases. MMPs, growth factors, and prometastatic and osteolytic factors clearly participate, but what is the precise interaction and how can this be exploited to improve therapy for bone metastases? In the August 15, 2009, issue of Genes \& Development, Lu et al. (2009) elegantly define these interactions at the molecular, cellular, and whole-animal level, followed by translation to the clinic. Previous work by Kang et al. (2003) set the stage for these studies in that ADAMTS1 and MMP-1 were increased in MDA-MB-231 breast cancer clones with high capacity to metastasize to bone. Using similar animal models, Lu et al. (2009) first showed that combined silencing of ADAMSTS1 and MMP-1 by shRNA dramatically reduced bone metastases in the bone metastatic MDA-MB-231 clones, while silencing of individual genes had no effect. This was associated with a dramatic reduction in osteoclast numbers at the tumor-bone interface on histologic sections of bone metastases. In contrast, overexpression of ADAMTS1 and $M M P-1$ together increased bone metastases and osteolysis in a weakly bone metastatic MDA-MB-231 clone, while single overexpression of the respective genes had no effect. The latter observations were extended to other cell lines-MCF-7 and MDA-MB-435-in that overexpression of both ADAMTS1 and MMP-1 together increased osteolytic bone metastases, while overexpression of ADAMTS or MMP-1 alone had no effect. Finally, another bone metastatic derivative from a breast cancer cell line derived from a pleural effusion showed high 
expression of both ADAMTS1 and MMP-1. Thus, the findings were consistent across multiple cell lines, as well as in a primary breast tumor model. Of note, the alterations in MMPs had no effect on tumor growth in the mammary fat pad, and suggested that the observed effects of MMPs were specific to the bone microenvironment.

Although in vitro invasion, assessed by tumor invasion through Matrigel or human bone marrow endothelial cell barriers, was reduced by ADAMTS1 or MMP-1 knockdown, the effect of these MMPs on osteolysis in vivo was not explained. They next showed that conditioned media from the MDA-MB-231 bone metastatic clones stimulated osteoclast formation from bone marrow cultures in vitro, while conditioned media from similar cells in which both ADAMTS1 and MMP-1 were knocked down had no effect. Conditioned media from the bone metastatic clones reduced the expression of $O P G$ and increased $R A N K L$ in a differentiated osteoblast cell line, MC3T3$\mathrm{E} 1$, while conditioned media from bone metastatic clones in which ADAMTS1 and MMP-1 were knocked down had robust expression of $O P G$. Since direct treatment of MC3T3-E1 did not alter the expression of $O P G$ or $R A N K L$, Lu et al. (2009) next used a human cytokine array to identify differentially expressed cytokines in the conditioned media from control, single- or double-knockdown clones of bone metastatic MDA-MB-231 cells. Only one cytokine, amphiregulin (AREG), was differentially expressed: increased in the bone metastatic clone and reduced in the double-knockdown clones. Further analysis showed that other EGF family members, heparinbound (HB)-EGF and TGF- $\alpha$, were also increased in conditioned media of bone metastatic MDA-MB-231, but EGF was not. The differential expression of these EGF family members was not regulated at the mRNA level, as assessed by Northern blot analysis, but rather at the post-translational level. Indeed, ADAMTS1 was shown by others to release membrane-bound EGF-like ligands (Liu et al. 2006) and Lu et al. (2009) showed that MMP-1 could proteolytically cleave AREG, HB-EGF, and TGF- $\alpha$.

EGFR family members have long been known to stimulate bone resorption (Ibbotson et al. 1986; Lorenzo et al. 1986; Takahashi et al. 1986). Recent investigation showed that the increased osteoclastogenesis is due to alterations of osteoblast-expressed RANKL and OPG (Zhu et al. 2007), as osteoclasts do not express EGRF. Lu et al. (2009) confirmed these observations to show that soluble recombinant AREG, HB-EGF, and TGF- $\alpha$ reduced the expression of OPG (but not RANKL) in different osteoblast lines. Furthermore, these ligands stimulated osteoclast formation in mouse bone marrow cultures, and this effect, as well as the effect on osteoblast $O P G$ expression, was blocked by EGFR-neutralizing antibody cetuximab or EGFR kinase inhibitor gefitinib. In the mouse model of bone metastases, these anti-EGFR therapies were both effective to reduce osteolytic bone metastases due to the highly bone metastatic MDAMB-231 clones. The effect was best when both the antibody and the kinase inhibitor were used together. Furthermore, these agents reduced tumor growth even when the tumors were injected directly into the bone site, just as they did when inoculated into the arterial circulation, but had no effect on tumor growth at the mammary fat pad. Consistent with the previous experiments, these results suggested that the effect of the EGFR blockade to reduce tumor growth was specific to the bone microenvironment. Finally, to assess the clinical relevance of these in vitro and mouse studies, Lu et al. (2009) assessed MMP-1 and ADAMTS1 in human samples from breast cancer patients. Increased serum MMP-1 concentrations correlated with the presence of bone metastases in 250 patients, while ADAMTS1 mRNA from 82 primary breast tumors was higher from patients who developed bone metastases.

Taken together, these studies indicate that MMPsspecifically, MMP-1 and ADAMTS1-trigger a cascade of events that promote osteolytic bone metastases in breast cancer. These MMPs cleave EGF ligands from the tumor surface that then bind EGFR on osteoblasts to suppress OPG and stimulate osteoclastogenesis. Each component of this cascade was established prior to this report: MMPs promote metastases, MMPs cleave EGF ligands, and EGF ligands stimulate osteoclastogenesis via alterations in osteoblast RANKL/OPG ratio. However, Lu et al. (2009) are the first to convincingly link these components together to demonstrate that this metastatic cascade has specific effects to promote osteolytic bone metastases. A potential role for MMPs in tumor-bone interactions at the site of metastases is illustrated in Figure 1. The elegant use of complementary in vitro and in vivo studies, the efficacy of EGFR inhibitors in vivo, and the analysis of human samples provide convincing rationale to target components of this pathway to treat bone metastases, as well as to engage larger prospective clinical trials to assess MMPs as prognostic markers for the development of bone metastases.

These studies implicate multiple molecular targets that could be exploited to expand the therapeutic armamentarium beyond the current bisphosphonate standard of care for bone metastases: MMPs, EGFR, and RANKL. Large phase III trials are under way using human monoclonal antibody to RANKL (denosumab) in patients with bone metastases, as phase II trials showed efficacy at least equivalent to bisphosphonates (Fizazi et al. 2009a,b; Body et al. 2009). Recent unpublished data indicate that denosumab treatment was superior to the bisphosphonate zoledronic acid to treat breast cancer bone metastases (Crook and Guise 2009). Small studies and anecdotal evidence suggest that anti-EGFR therapy is beneficial in patients with bone metastases due to lung and breast cancer (Albain et al. 2002; von Minckwitz et al. 2003; Sugiura et al. 2008; Zampa et al. 2008). Indeed, anti-EGFR therapy was highly effective in treating bone pain in a phase II study of patients with breast cancer and bone metastases (Albain et al. 2002; von Minckwitz et al. 2003). These studies also support a bone-specific role for EGFR signaling in bone metastases, as anti-EGFR treatment is not particularly effective as a single agent. Previous large clinical trials of MMP inhibitors in generalized metastases have been largely unsuccessful. Thus, 


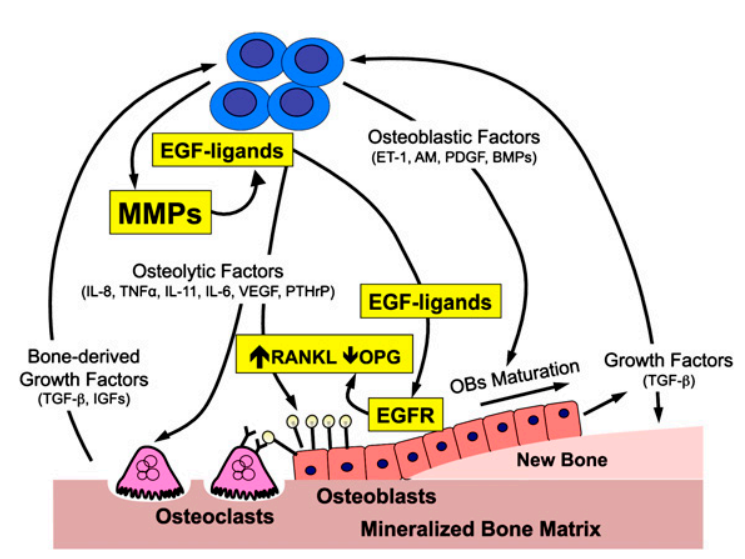

Figure 1. Potential role for MMPs in the bone microenvironment at sites of solid tumor metastases. Tumors secrete (1) osteolytic factors (PTHrP, IL-11, IL-6, IL-8, VEGF, etc.) that stimulate osteoclastic bone resorption either directly or indirectly by increasing the ration of RANKL to OPG, and (2) osteoblastic factors (ET-1, adrenomedullin [AM], plateletderived growth factor [PDGF] and BMPs) that stimulate osteoblast proliferation and differentiation. The osteoblasts secrete proteins and growth factors (TGF- $\beta$ and IGFs) that are deposited into mineralized bone matrix and enhance the local microenvironment surrounding the tumor cells. Osteoclastic bone resorption causes release and activation of these proteins to further enhance the local milieu. Studies by $\mathrm{Lu}$ et al. (2009) (highlighted here in yellow) indicate that tumor-produced MMPs (MMP-1 and ADAMTS1) may contribute to these interactions by cleaving membrane-bound EGF-like growth factors (EGF ligands: AREG, HB-EGF, and TGF- $\alpha$ ) that bind EGFR in osteoblasts to suppress OPG and increase the ratio of RANKL to OPG to favor osteoclastogenesis. Other possible roles for MMPs in this process (not shown in this schematic) include cleavage of collagen at the bone surface to enhance bone resorption mediated by osteolytic factors, cleavage, activation of tumor-expressed RANKL, and activation of other growth factors (such as TGF- $\beta$, IGFs, and others) that can further fuel this vicious cycle.

success may depend on selecting the appropriate patient population to treat with the inhibitors, or targeting only the downstream effectors EGFR or RANKL. The latter approach may result in a better safety profile than targeting the MMPs.

In addition to these therapeutic implications, the provocative data presented by $\mathrm{Lu}$ et al. (2009) raise many questions. Will targeted therapy for bone metastases with MMP inhibitors, EGFR inhibitors, or anti-RANKL therapy be superior to the standard of care with bisphosphonates, since all have the same effect to decrease osteoclastic bone resorption? The mechanisms by which bisphosphonates inhibit bone resorption differ from the mechanisms resulting from blockade of the RANKL signaling triad, as the former induces osteoclast apoptosis and the latter blocks osteoclastogenesis. The result is that osteoclasts will still be present in the bones of bisphosphonate-treated patients, even though the cells are detached from bone and not actively resorbing. The osteoclast is a potential source of bone-active factors, such as IL-6 and MMPs. Blockade of EGFR and RANKL, or both, would abolish the osteoclast source of autocrine and paracrine factors. Further, RANKL and EGF ligands may also signal to cancer cells that express those receptors, independent of the effects on osteoclastogenesis (Armstrong et al. 2008); direct anti-tumor effects may also be realized. There is emerging data that bisphosphonates exert antitumor effects in vivo (Daubiné et al. 2007), but the mechanisms likely differ from potential anti-tumor effects of anti-EGFR or RANKL therapy. Could these therapies be used in conjunction with bisphosphonates to have additive effects or to lower the bisphosphonate dose in cancer patients and potentially reduce the risk of osteonecrosis of the jaw? Detailed preclinical studies of dosing therapy alone or in combination will be needed to address some of these questions. Will anti-EGFR or antiRANKL therapy be associated with osteonecrosis of the jaw? It is still not clear if this association of osteonecrosis of the jaw to bisphosphonates is a class effect or associated with any drug that inhibits osteoclastic bone resorption. These and other questions will require detailed preclinical and large-scale clinical studies with appropriate bonespecific outcome measures before we can make conclusions. However, it is clear from these and a growing body of experimental and clinical data that the microenvironment in which a tumor cell resides does matter, and future therapies will need to be directed in a site-specific manner to optimize our chances of curing the devastating consequences of tumor metastases to bone.

\section{Acknowledgments}

T.A.G. is supported by NIH grants CA69158, DK065837, and DK067333; the V-Foundation; Mary K. Ash; and Indiana University.

\section{References}

Albain KS, Elledge R, Gradishar WJ, Hayes DF, Rowinsky E, Hudis C, Pusztai L, Tripathy D, Modi S, Rubi S. 2002. Openlabel, phase II, multicenter trial of ZD1839 ('Iressa') in patients with advanced breast cancer. Breast Cancer Res Treat 76: S33. Abstract 20. doi: 10.1023/A:1021560101414.

Armstrong AP, Miller RE, Jones JC, Zhang J, Keller ET, Dougall WC. 2008. RANKL acts directly on RANK-expressing prostate tumor cells and mediates migration and expression of tumor metastasis genes. Prostate 68: 92-104.

Bachmeier BE, Nerlich AG, Lichtinghagen R, Sommerhoff CP. 2001. Matrix metalloproteinases (MMPs) in breast cancer cell lines of different tumorigenicity. Anticancer Res 21: 3821-3828.

Bendre MS, Montague DC, Peery T, Akel NS, Gaddy D, Suva LJ. 2003. Interleukin-8 stimulation of osteoclastogenesis and bone resorption is a mechanism for the increased osteolysis of metastatic bone disease. Bone 33: 28-37.

Body JJ, Lipton A, Gralow J, Steger GG, Gao G, Yeh H, Fizazi K. 2009. Effects of denosumab in patients with bone metastases, with and without previous bisphosphonate exposure. I Bone Miner Res. doi: 10.1359/jbmr.090810.

Brown JE, Cook RJ, Major P, Lipton A, Saad F, Smith M, Lee KA, Zheng M, Hei YJ, Coleman RE. 2005. Bone turnover markers as predictors of skeletal complications in prostate cancer, lung cancer, and other solid tumors. I Natl Cancer Inst 97: 59-69. 
Coleman RE. 2009. Adjuvant bisphosphonates in breast cancer: Are we witnessing the emergence of a new therapeutic strategy? Eur J Cancer 45: 1909-1915.

Cook RJ, Coleman R, Brown J, Lipton A, Major P, Hei YJ, Saad F, Smith MR. 2006. Markers of bone metabolism and survival in men with hormone-refractory metastatic prostate cancer. Clin Cancer Res 12: 3361-3367.

Costa LA, Alho I, Casimiro S, Oliveira AG, Luís I, Fernandes A, Bicho M, Ali SM, Leitzel K, Demers L, et al. 2008. Markers of bone turnover (ICTP, NTX) and serum matrix metalloproteinase 1 (MMP1) as prognostic markers in breast cancer patients (BC) with bone metastases (BM) treated with bisphosphonates (BP). J Clin Oncol 26 (Suppl.): Abstract 1024. http://meeting. ascopubs.org/cgi/content/abstract/26/15_suppl/1024.

Coussens LM, Fingleton B, Matrisian LM. 2002. Matrix metalloproteinase inhibitors and cancer: Trials and tribulations. Science 295: 2387-2392.

Crook MK, Guise TA. 2009. RANKL: Targeting bone and cancer to treat skeletal complications of malignancy. IBMS BoneKEy (in press).

Daubiné F, Le Gall C, Gasser J, Green J, Clézardin P. 2007. Antitumor effects of clinical dosing regimens of bisphosphonates in experimental breast cancer bone metastasis. I Natl Cancer Inst 99: 322-330.

Dougall WC, Glaccum M, Charrier K, Rohrbach K, Brasel K, De Smedt T, Daro E, Smith J, Tometsko ME, Maliszewski CR, et al. 1999. RANK is essential for osteoclast and lymph node development. Genes \& Dev 13: 2412-2424.

Egeblad M, Werb Z. 2002. New functions for the matrix metalloproteinases in cancer progression. Natl Rev 2: 161-174.

Fizazi K, Lipton A, Mariette X, Body JJ, Rahim Y, Gralow JR, Gao G, Wu L, Sohn W, Jun S. 2009a. Randomized phase II trial of denosumab in patients with bone metastases from prostate cancer, breast cancer, or other neoplasms after intravenous bisphosphonates. J Clin Oncol 27: 1564-1571.

Fizazi K, Bosserman L, Gao G, Skacel T, Markus R. 2009b. Denosumab treatment of prostate cancer with bone metastases and increased urine N-telopeptide levels after therapy with intravenous bisphosphonates: Results of a randomized phase II trial. I Urol 82: 509-515.

Horwood NJ, Elliott J, Martin TJ, Gillespie MT. 1998. Osteotropic agents regulate the expression of osteoclast differentiation factor and osteoprotegerin in osteoblastic stromal cells. Endocrinology 139: 4743-4746.

Ibbotson KJ, Harrod J, Gowen M, D'Souza S, Smith DD, Winkler ME, Derynck R, Mundy GR. 1986. Human recombinant transforming growth factor $\alpha$ stimulates bone resorption and inhibits formation in vitro. Proc Natl Acad Sci 83: 2228-2232.

James ND, Caty A, Borre M, Zonnenberg BA, Beuzeboc P, Morris T, Phung D, Dawson NA. 2009. Safety and efficacy of the specific endothelin-A receptor antagonist ZD4054 in patients with hormone-resistant prostate cancer and bone metastases who were pain free or mildly symptomatic: A double-blind, placebo-controlled, randomised, phase 2 trial. Eur Urol 55: 1112-1123.

John A, Tuszynski G. 2001. The role of matrix metalloproteinases in tumor angiogenesis and tumor metastasis. Pathol Oncol Res 7: 14-22.

Jones DH, Nakashima T, Sanchez OH, Kozieradzki I, Komarova SV, Sarosi I, Morony S, Rubin E, Sarao R, Hojilla CV, et al 2006. Regulation of cancer cell migration and bone metastasis by RANKL. Nature 440: 692-696.

Kang Y, Siegel PM, Shu W, Drobnjak M, Kakonen SM, CordonCardo C, Guise TA, Massague J. 2003. A multigenic program mediating breast cancer metastasis to bone. Cancer Cell 3: 537-549.
Khosla S, Burr D, Cauley J, Dempster DW, Ebeling PR, Felsenberg D, Gagel RF, Gilsanz V, Guise T, Koka S, et al. 2007. American Society for Bone and Mineral Research. Bisphosphonateassociated osteonecrosis of the jaw: Report of a task force of the American Society for Bone and Mineral Research. J Bone Miner Res 22: 1479-1491.

Klein A, Olendrowitz C, Schmutzler R, Hampl J, Schlag PM, Maass N, Arnold N, Wessel R, Ramser J, Meindl A, et al. 2009. Identification of brain- and bone-specific breast cancer metastasis genes. Cancer Lett 276: 212-220.

Kong YY, Yoshida H, Sarosi I, Tan HL, Timms E, Capparelli C, Morony S, Oliveira-dos-Santos AJ, Van G, Itie A, et al. 1999. OPGL is a key regulator of osteoclastogenesis, lymphocyte development and lymph-node organogenesis. Nature 397: 315-323.

Korpal M, Yan J, Lu X, Xu S, Lerit DA, Kang Y. 2009. Imaging transforming growth factor- $\beta$ signaling dynamics and therapeutic response in breast cancer bone metastasis. Nat Med 15: 960-966.

Krane SM, Inada M. 2008. Matrix metalloproteinases and bone. Bone 43: 7-18.

Kumar S, Hand AT, Connor JR, Dodds RA, Ryan PJ, Trill JJ, Fisher SM, Nuttall ME, Lipshutz DB, Zou C, et al. 1999. Identification and cloning of a connective tissue growth factor-like cDNA from human osteoblasts encoding a novel regulator of osteoblast functions. J Biol Chem 74: 17123-17131.

Lacey DL, Timms E, Tan HL, Kelley MJ, Dunstan CR, Burgess T, Elliott R, Colombero A, Elliott G, Scully S, et al. 1998. Osteoprotegerin ligand is a cytokine that regulates osteoclast differentiation and activation. Cell 93: 165-176.

Lipton A, Costa L, Ali S, Demers L. 2001. Use of markers of bone turnover for monitoring bone metastases and the response to therapy. Semin Oncol 28: 54-59.

Lipton A, Small E, Saad F, Gleason D, Gordon D, Smith M, Rosen L, Kowalski MO, Reitsma D, Seaman J. 2002. The new bisphosphonate, Zometa (zoledronic acid), decreases skeletal complications in both osteolytic and osteoblastic lesions: A comparison to pamidronate. Cancer Invest 20: 45-54.

Liu YJ, Xu Y, Yu Q. 2006. Full-length ADAMTS-1 and the ADAMTS-1 fragments display pro- and antimetastatic activity, respectively. Oncogene 25: 2452-2467.

Lorenzo JA, Quinton J, Sousa S, Raisz LG. 1986. Effects of DNA and prostaglandin synthesis inhibitors on the stimulation of bone resorption by epidermal growth factor in fetal rat longbone cultures. J Clin Invest 77: 1897-1902.

Lu X, Wang Q, Hu G, Van Poznak C, Fleisher M, Reiss M, Massagué J, Kang Y. 2009. ADAMTS1 and MMP1 proteolytically engage EGF-like ligands in an osteolytic signaling cascade for bone metastasis. Genes \& Dev 23: 1882-1894.

Lynch CC, Hikosaka A, Acuff HB, Martin MD, Kawai N, Singh RK, Vargo-Gogola TC, Begtrup JL, Peterson TE, Fingleton B, et al. 2005. MMP-7 promotes prostate cancer-induced osteolysis via the solubilization of RANKL. Cancer Cell 7: 485-496.

Mohammad KS, Chen CG, Balooch G, Stebbins E, McKenna $\mathrm{CR}$, Davis $\mathrm{H}$, Niewolna $\mathrm{M}$, Peng $\mathrm{XH}$, Nguyen DH, IonovaMartin SS, et al. 2009. Pharmacologic inhibition of the TGF- $\beta$ type I receptor kinase has anabolic and anti-catabolic effects on bone. PLoS One 4: e5275. doi: 10.1371/journal. pone. 0005275 .

Mundy GR. 2002. Metastasis to bone: Causes, consequences and therapeutic opportunities. Natl Rev 2: 584-593.

Nabha SM, Santos EB, Yamamoto HA, Belizi A, Dong Z, Meng H, Saliganan A, Sabbota A, Bonfil RD, Cher ML. 2008. Bone marrow stromal cells enhance prostate cancer cell invasion through type I collagen in an MMP-12 dependent manner. Int J Cancer 122: 2482-2490. 
Nakopoulou L, Katsarou S, Giannopoulou I, Alexandrou P, Tsirmpa I, Panayotopoulou E, Mavrommatism J, Keramopoulos A. 2002. Correlation of tissue inhibitor of metalloproteinase-2 with proliferative activity and patients' survival in breast cancer. Mod Pathol 15: 26-34.

Nakopoulou L, Tsirmpa I, Alexandrou P, Louvrou A, Ampela C, Markaki S, Davaris PS. 2003. MMP-2 protein in invasive breast cancer and the impact of MMP-2/TIMP-2 phenotype on overall survival. Breast Cancer Res Treat 77: 145-155.

Nemeth JA, Yousif R, Herzog M, Che M, Upadhyay J, Shekarriz B, Bhagat S, Mullins C, Fridman R, Cher ML. 2002. Matrix metalloproteinase activity, bone matrix turnover, and tumor cell proliferation in prostate cancer bone metastasis. I Natl Cancer Inst 94: 17-25.

Palmqvist P, Persson E, Conaway HH, Lerner UH. 2002. IL-6, leukemia inhibitory factor, and oncostatin $\mathrm{M}$ stimulate bone resorption and regulate the expression of receptor activator of NF- $\mathrm{kB}$ ligand, osteoprotegerin, and receptor activator of NF- $\mathrm{B}$ in mouse calvariae. I Immunol 169: 3353-3362.

Ranuncolo SM, Armanasco E, Cresta C, Bal De Kier Joffe E, Puricelli L. 2003. Plasma MMP-9 (92 kDa-MMP) activity is useful in the follow-up and in the assessment of prognosis in breast cancer patients. Int I Cancer 106: 745-751.

Roodman GD. 2004. Mechanisms of bone metastasis. N Engl J Med 350: 1655-1664.

Saad F, Gleason DM, Murray R, Tchekmedyian S, Venner P, Lacombe L, Chin JL, Vinholes JJ, Goas JA, Chen B. Zoledronic Acid Prostate Cancer Study Group. 2002. A randomized, placebo-controlled trial of zoledronic acid in patients with hormone-refractory metastatic prostate carcinoma. I Natl Cancer Inst 94: 1458-1468.

Simonet WS, Lacey DL, Dunstan CR, Kelley M, Chang MS, Luthy R, Nguyen HQ, Wooden S, Bennett L, Boone T, et al. 1997. Osteoprotegerin: A novel secreted protein involved in the regulation of bone density. Cell 89: 309-319.

Sugiura H, Yamada K, Sugiura T, Hida T, Mitsudomi T. 2008. Predictors of survival in patients with bone metastasis of lung cancer. Clin Orthop Relat Res 466: 729-736.

Sun YX, Schneider A, Jung Y, Wang J, Dai J, Wang J, Cook K, Osman NI, Koh-Paige AJ, Shim H, et al. 2005. Skeletal localization and neutralization of the SDF-1(CXCL12)/ CXCR4 axis blocks prostate cancer metastasis and growth in osseous sites in vivo. J Bone Miner Res 20: 318-329.

Takahashi N, MacDonald BR, Hon J, Winkler ME, Derynck R, Mundy GR, Roodman GD. 1986. Recombinant human transforming growth factor- $\alpha$ stimulates the formation of osteoclast-like cells in long-term human marrow cultures. J Clin Invest 78: 894-898.

Thomas RJ, Guise TA, Yin JJ, Elliott J, Horwood NJ, Martin TJ, Gillespie MT. 1999. Breast cancer cells interact with osteoblasts to support osteoclast formation. Endocrinology 140: 4451-4458.

Tsuda E, Goto M, Mochizuki S, Yano K, Kobayashi F, Morinaga T, Higashio K. 1997. Isolation of a novel cytokine from human fibroblasts that specifically inhibits osteoclastogenesis. Biochem Biophys Res Commun 234: 137-142.

Upadhyay J, Shekarriz B, Nemeth JA, Dong Z, Cummings GD, Fridman R, Sakr W, Grignon DJ, Cher ML. 1999. Membrane type 1-matrix metalloproteinase (MT1-MMP) and MMP-2 immunolocalization in human prostate: Change in cellular localization associated with high-grade prostatic intraepithelial neoplasia. Clin Cancer Res 5: 4105-4110.

von Minckwitz G, Jonat W, Beckmann M, De Bois A, Kleeberg U, Kuhnie H, Kettner E, Hilfrich J, Torode J, Schneeweiss A. 2003. A multicenter phase II trial to evaluate gefitinib (Iressa, ZD1839) (500mg/day) in patients with metastatic breast cancer after previous chemotherapy treatment. Euro I Cancer 1: S133.

Yin JJ, Selander K, Chirgwin JM, Dallas M, Grubbs BG, Wieser R, Massagué J, Mundy GR, Guise TA. 1999. TGF- $\beta$ signaling blockade inhibits PTHrP secretion by breast cancer cells and bone metastases development. J Clin Invest 103: 197-206.

Yin JJ, Mohammad KS, Kakonen SM, Harris S, Wu-Wong JR, Wessale JL, Padley RJ, Garrett IR, Chirgwin JM, Guise TA. 2003. A causal role for endothelin-1 in the pathogenesis of osteoblastic bone metastases. Proc Natl Acad Sci 100: 10954-10959.

Yoneda T, Sasaki A, Dunstan C, Williams PJ, Bauss F, De Clerck YA, Mundy GR. 1997. Inhibition of osteolytic bone metastasis of breast cancer by combined treatment with the bisphosphonate ibandronate and tissue inhibitor of the matrix metalloproteinase-2. J Clin Invest 99: 2509-2517.

Zampa G, Moscato M, Brannigan BW, Morabito A, Bell DW, Normanno N. 2008. Prolonged control of bone metastases in non-small-cell lung cancer patients treated with gefitinib. Lung Cancer 60: 452-454.

Zhao W, Byrne MH, Wang Y, Krane SM. 2000. Osteocyte and osteoblast apoptosis and excessive bone deposition accompany failure of collagenase cleavage of collagen. J Clin Invest 106: 941-949.

Zhu J, Jia X, Xiao G, Kang Y, Partridge NC, Qin L. 2007. EGFlike ligands stimulate osteoclastogenesis by regulating expression of osteoclast regulatory factors by osteoblasts: Implications for osteolytic bone metastases. I Biol Chem 282: 26656-26664. 


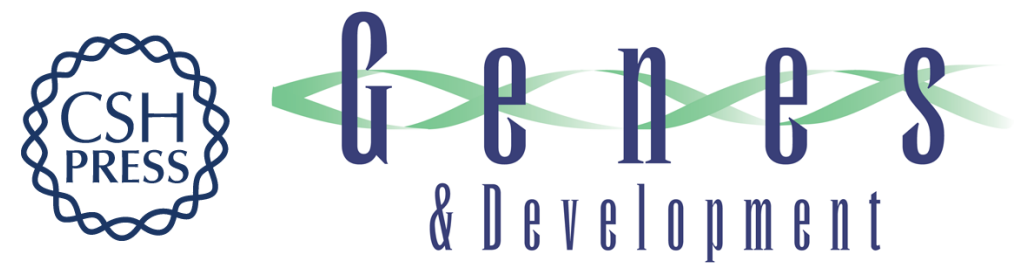

\section{Breaking down bone: new insight into site-specific mechanisms of breast cancer osteolysis mediated by metalloproteinases}

Theresa A. Guise

Genes Dev. 2009, 23:

Access the most recent version at doi:10.1101/gad.1854909
Related Content ADAMTS1 and MMP1 proteolytically engage EGF-like ligands in an osteolytic signaling cascade for bone metastasis
Xin Lu, Qiongqing Wang, Guohong Hu, et al.
Genes Dev. August , 2009 23: 1882-1894
References This article cites 57 articles, 10 of which can be accessed free at:
http://genesdev.cshlp.org/content/23/18/2117.full.html\#ref-list-1
Articles cited in:
http://genesdev.cshlp.org/content/23/18/2117.full.html\#related-urls

\section{License}
Email Alerting
Service
Receive free email alerts when new articles cite this article - sign up in the box at the top right corner of the article or click here.

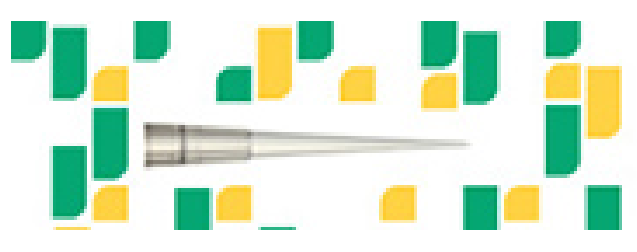

Focused on your science. 